This item was submitted to Loughborough's Research Repository by the author.

Items in Figshare are protected by copyright, with all rights reserved, unless otherwise indicated.

\title{
Nonlinear pricing and tariff differentiation: evidence from the British electricity market
}

PLEASE CITE THE PUBLISHED VERSION

http://dx.doi.org/10.5547/01956574.35.1.4

\section{PUBLISHER}

(C) International Association of Energy Economics (IAEE)

LICENCE

CC BY-NC-ND 4.0

\section{REPOSITORY RECORD}

Davies, Stephen, Catherine Waddams Price, and Chris M. Wilson. 2019. "Nonlinear Pricing and Tariff Differentiation: Evidence from the British Electricity Market”. figshare. https://hdl.handle.net/2134/15289. 
This item was submitted to Loughborough's Institutional Repository (https://dspace.lboro.ac.uk/) by the author and is made available under the following Creative Commons Licence conditions.

\section{creative
commons}

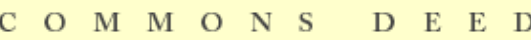

Attribution-NonCommercial-NoDerivs 2.5

You are free:

- to copy, distribute, display, and perform the work

Under the following conditions:

Attribution. You must attribute the work in the manner specified b the author or licensor.

Noncommercial. You may not use this work for commercial purposes.

No Derivative Works. You may not alter, transform, or build upon this work.

- For any reuse or distribution, you must make clear to others the license terms of this work.

- Any of these conditions can be waived if you get permission from the copyright holder.

Your fair use and other rights are in no way affected by the above.

This is a human-readable summary of the Leqal Code (the full license).

\section{Disclaimer 만}

For the full text of this licence, please go to: http://creativecommons.org/licenses/by-nc-nd/2.5/ 

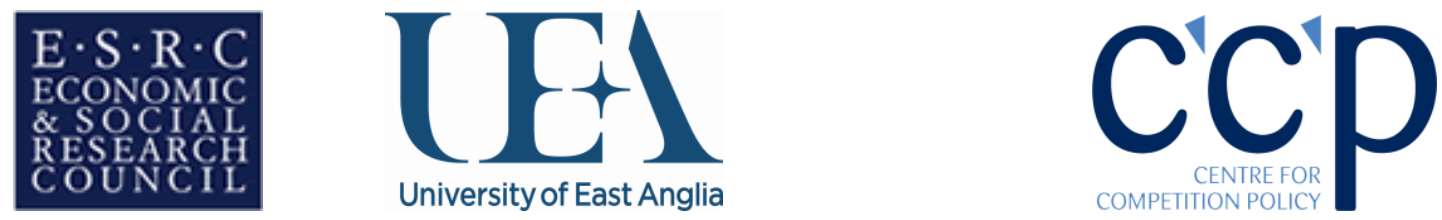

\title{
Nonlinear Pricing and Tariff Differentiation
}

\author{
Stephen Davies \\ ESRC Centre for Competition Policy, University of East \\ Anglia
}

Catherine Waddams Price

ESRC Centre for Competition Policy, University of East

Anglia

\&

Chris M. Wilson

School of Business and Economics, Loughborough

University

\section{CCP Working Paper 12-2}

\begin{abstract}
Liberalisation of the British electricity market, in which previously monopolised regional markets were exposed to large-scale entry, is used to assess the propositions of recent theory on oligopolistic nonlinear pricing. Consistent with the theory, each oligopolist offered a single two-part electricity tariff, but inconsistent with the theory, we show that the two-part tariffs are heterogeneous in ways that cannot be attributed to asymmetric costs or variations in brand loyalty or market frictions. Instead, we present evidence to suggest that firms differentiated their tariff structures with the result of segmenting the market according consumers' usage patterns.

December 2011
\end{abstract}


Acknowledgements: The financial support of the Economic and Social Research Council (ESRC) is gratefully acknowledged. We thank Khac Pham and Hieu Tran for their excellent research assistance. We appreciate helpful comments from Mark Armstrong, Severin Borenstein, Paul Dobson, Morten Hviid, Stephen Littlechild, John Vickers, Mike Waterson and participants at presentations at: NIE in Leicester, EARIE in Ljubljana, the Electricity Policy Research Group in Cambridge, IOS at Atlanta, the Competition Law and Economics European Network workshop in Bonn, Norges Han-delshøyskole in Bergen, DICE in Dusseldorf, and the Centre for Competition Policy, Norwich. A previous and substantially different version of the paper was circulated under the title "How Far Does Economic Theory Explain Competitive Nonlinear Pricing in Practice?"

Contacts Details:

Corresponding author: Stephen Davies: s.w.davies@uea.ac.uk 


\title{
Nonlinear Pricing and Tariff Differentiation
}

\author{
Stephen Davies, Catherine Waddams Price*and Chris M. Wilson ${ }^{\dagger \ddagger}$
}

December 2011

\begin{abstract}
Liberalisation of the British electricity market, in which previously monopolised regional markets were exposed to large-scale entry, is used to assess the propositions of recent theory on oligopolistic nonlinear pricing. Consistent with the theory, each oligopolist offered a single two-part electricity tariff, but inconsistent with the theory, we show that the two-part tariffs are heterogeneous in ways that cannot be attributed to asymmetric costs or variations in brand loyalty or market frictions. Instead, we present evidence to suggest that firms differentiated their tariff structures with the result of segmenting the market according consumers' usage patterns.
\end{abstract}

${ }^{*}$ ESRC Centre for Competition Policy, University of East Anglia.

${ }^{\dagger}$ School of Business and Economics, Loughborough University.

${ }^{\ddagger}$ The financial support of the Economic and Social Research Council (ESRC) is gratefully acknowledged. We thank Khac Pham and Hieu Tran for their excellent research assistance. We appreciate helpful comments from Mark Armstrong, Severin Borenstein, Paul Dobson, Morten Hviid, Stephen Littlechild, John Vickers, Mike Waterson and participants at presentations at: NIE in Leicester, EARIE in Ljubljana, the Electricity Policy Research Group in Cambridge, IOS at Atlanta, the Competition Law and Economics European Network workshop in Bonn, Norges Handelshøyskole in Bergen, DICE in Dusseldorf, and the Centre for Competition Policy, Norwich. A previous and substantially different version of the paper was circulated under the title "How Far Does Economic Theory Explain Competitive Nonlinear Pricing in Practice?" Corresponding author details: s.w.davies@uea.ac.uk 


\section{Introduction}

Nonlinear pricing is frequently observed in real world oligopolistic markets, often in the form of quantity discounts which are not totally explicable in terms of costs. Yet the theory of oligopolistic nonlinear pricing (or second degree price discrimination more generally) remains incomplete and largely untested. In a significant development, two papers (Armstrong and Vickers, 2001 and Rochet and Stole, 2002) derive the striking result that, in any symmetric equilibrium, firms should offer single twopart tariffs that are cost-based in the sense that marginal prices are equal to marginal costs.

This paper uses the liberalisation of the British retail electricity industry to examine how these and other theoretical predictions compare to the outcomes in this particular case of oligopolistic tariff competition. Consistent with the theory, we find that each oligopolist offered a single two-part electricity tariff, but inconsistent with the theory, we show that the two-part tariffs are heterogeneous across firms. Throughout the time period and across all geographical regions, we demonstrate that relative to the incumbent, entrants typically selected tariffs with a higher fixed fee and a lower marginal price. Similarly, there were also systematic variations amongst the entrants' tariffs and rather than diminishing, these asymmetries increased over the time period. These tariff asymmetries cannot be attributed to asymmetric costs or the existence of brand loyalty or market frictions. Instead, we put forward evidence to suggest that firms may have differentiated their tariff structures with the effect of segmenting the market according to consumers' usage patterns, with some firms offering tariffs that are more attractive to lower volume consumers and other firms offering tariffs targeted consumers with higher usage. Indeed, by the end of the studied period, it is interesting to note that, collectively, the seven firms provided a range of different two part tariffs which qualitatively resembled a monopolist's optimal menu of two-part tariffs. As there is no current theoretical explanation for these findings we conclude that future theoretical work should give more focus to the possibility of 
tariff asymmetries.

The existing empirical literature on nonlinear pricing has expanded considerably in recent years. For example, Leslie (2004) estimates the welfare effects of price discrimination at a Broadway theatre; Cohen (2008) demonstrates that $35-45 \%$ of the unit price variation in paper towels is consistent with price discrimination; and several papers show how increases in competition can i) increase the number of pricing options offered by firms (Borzekowski et al., 2009 and Seim and Viard, 2011); and ii) reduce the level of firms' tariffs, with a greater reduction in the level of tariffs aimed at consumers with higher usage (Miravete and Röller, 2004; Busse and Rysman, 2005; and Seim and Viard 2011). Closer to the topic of our paper, McManus (2007) examines the empirical implications of Armstrong and Vickers (2001) and Rochet and Stole (2002) in the context of product size in the specialty coffee market. Consistent with their predictions of marginal cost pricing, he finds that product sizes in the most competitive product category are close to the efficient level.

However, by concentrating on empirical regularities at the market level, the literature has paid little attention to the potential asymmetries between firms' pricing strategies. These asymmetries form the main focus of our paper. As part of a wider study, Miravete (2011) considers some forms of tariff asymmetries in the early US cellular industry duopolies. He finds that, relative to the entrant, the incumbent selected a (temporarily) more complex tariff schedule and used a greater share of dominated tariff options. In our oligopoly context, we find a related result in that entrants offered tariffs that dominated the incumbent's in approximately $25 \%$ of cases. However, our paper differs from Miravete (2011) in that we focus on asymmetries in tariff structures. In particular, we use a simple summary statistic for any two-part tariff, which we term the Fixed to Marginal (FM) Ratio - the ratio of charges collected via the fixed fee to charges collected through the marginal price for the median consumer. Contrary to current theory, we find an increasing tendency for each entrant's FM ratio to differ systematically relative to both the incumbent and the other entrants, 
with the effect of segmenting the market according to consumption volume.

The next section introduces the market and section 3 summarises the recent theoretical literature. The data and some initial findings are presented in section 4. The remaining sections further explore the heterogeneity amongst firms' tariffs: Section 5 establishes that they cannot be explained by cost asymmetries, brand loyalty or market frictions, and section 6 shows that they imply a robust and systematic strategic segmentation of the market, according to the consumers' usage patterns. Section 7 discusses and concludes.

\section{The Market}

The electricity industry in Great Britain comprises four vertical stages - generation, transmission, distribution and retail. The focus of the present paper is on the retail stage, although there are significant vertical linkages (as discussed below). The retail sector was traditionally separated into 14 geographical regions, each with an incumbent monopolist; consumers were only able to buy from their local incumbent, and arbitrage was not possible. The industry was privatised in 1990/1, and the household retail sector was opened to competition in 1998/9. Thereafter, significant entry occurred and consumers were free to switch away from their incumbent (or any subsequent supplier) to any supplier within their region without financial penalty. The average prices of incumbents (although not entrants) continued to be regulated until April 2002, but no effective regulatory constraint was imposed on tariff structures for either incumbents or entrants (Harker and Waddams Price 2007). Indeed, the freedom of suppliers to offer alternative tariff structures was confirmed in the privatisation act that explicitly permits, but does not mandate, two part tariffs (Electricity Act 1989 Section 18(3)).

The product is essentially homogenous but households vary significantly in their levels of consumption. In all regions, the volume distribution of household consumption is positively skewed and approximately lognormal. Figure 1 shows the aggregate 
national distribution. Traditionally, public statistical sources (e.g. Ofgem 2003, p.49) report comparative data for low, medium and high consumption households, defined respectively as 1650, 3300 and $4950 \mathrm{kWh} /$ year. These levels will also be employed later in this paper, and as can be seen from the Figure, they approximately identify the four quartiles.

Firms are required to offer three alternative payment methods between which consumers are free to choose (standard credit, direct debit and prepayment) and they typically offer different tariffs for each ${ }^{1}$. Nearly all electricity suppliers were also active in the gas market, which had been liberalised over the previous two years. Suppliers have increasingly participated in mixed bundling by offering a 'dual-supply' or 'dual-fuel' discount to consumers who buy both fuels from the same firm.

Following liberalisation, there was almost $100 \%$ cross-entry by the original regional incumbents into each others' markets. The incumbent gas supplier, British Gas, also entered all regions, as did a few small Independents, see Table 1. Later, there was a gradual exit of Independents, but the main feature was the steady consolidation amongst incumbents. This began around the time of liberalisation, with the acquisition of four of the smaller incumbents, and continued over the following four years with the purchase of five other incumbents. By autumn 2002, the surviving electricity retailers had consolidated into 5 large companies, referred to here as the 'Majors'. By the beginning of 2006, these five firms (each now owning ex-incumbents in two or three regions) and British Gas were the only suppliers ${ }^{2}$.

\footnotetext{
${ }^{1}$ These are effectively three separate markets, catering for self-selecting consumers who opt for different billing arrangements, rather than a single market with multiple tariff options. Under standard credit, consumers receive a bill every three months for the previous quarter's consumption. Direct debit consumers agree for the supplier to withdraw a specified amount from the consumer's bank account at regular intervals, based on estimated annual consumption. Prepayment consumers pay in advance for consumption, usually by loading cash credit onto a payment card, similar to pay-as-you-go phones.

${ }^{2}$ Other very small independent companies have entered since, but most have not survived long.
} 
In the other vertical stages, these six firms are all integrated into electricity generation; electricity transmission is provided by the National Grid (a regulated privatized monopolist) and there is a monopoly distributor in each region (sometimes one of the Majors) that is required to serve all retailers on identical, published, regulated terms.

Thus in any regional market, there were up to five different types of firm:

- The Incumbent within its home region

- British Gas - an entrant into electricity, but the incumbent and previous monopoly gas supplier in each region

- Majorsaway - the four major incumbents from other regions

- Mini-Majorsaway - the other original incumbents who were acquired by the Majorsaway during the first half of the period

- Independents - with no region of previous incumbency.

In principle, there were two potential sources of asymmetry between these five types. First, the Incumbents, Majorsaway and British Gas were all integrated upstream into generation, while the Mini-Majorsaway (with one exception) and Independents were not. Second, relative to entrants, Incumbents may have been favoured by consumers due to the existence of brand loyalty or search and switching costs. This would probably have disadvantaged the entrant British Gas less heavily for two reasons: (i) most consumers would have already interacted with British Gas through past experience within the gas market, and (ii) with liberalisation, came the possibility of bundling gas and electricity and so for any consumer considering whether to buy both fuels from a single supplier, British Gas was just as much the incumbent as the customer's existing electricity supplier (Hviid and Waddams Price, 2011). These sources of asymmetry are discussed further in Section 5 .

Disaggregated data on market shares by firm and region over time are unavailable, but in the seven years after liberalisation, nearly half of consumers switched away from their regional electricity incumbents (Ofgem, 2006). From Table 2, we see that the average market share of original incumbents in their home region was just over 
$50 \%$ by 2005, with British Gas accounting for about 23\%, and the Majorsaway for another 23\%. In 2005 the Independents accounted for around 1\% of the market (Ofgem (2006), p. 18). A major reason why British Gas was the most successful entrant derives from the fairly widespread switching to dual-fuel tariffs. By 2004, $80 \%$ of switching in the energy market was to dual fuel deals (Ofgem (2004) p. 78).

\section{Theoretical Literature}

This section reviews the relevant models of nonlinear pricing, before assessing how closely their assumptions conform to the features of this particular market. We conclude that there is no relevant theoretical explanation, consistent with our later empirical findings, for why firms might select asymmetric non-cost based tariffs.

For monopoly, the standard results of nonlinear pricing are well known (e.g. Mussa and Rosen 1978 and Maskin and Riley 1984). Consumers are assumed to possess private information about their tastes, with higher types having a higher marginal utility over all units. If, in addition, consumers have a type-independent outside option, the monopolist's optimal price-quantity schedule can be shown to be concave such that higher types are offered a lower average price per unit. Equiv-

alently, the monopolist can mimic this schedule by offering a menu (continuum) of two-part tariffs, with decreasing marginal prices, $p$, and increasing fixed fees, $F$, such that higher types optimally select a tariff with a lower marginal price and a higher fixed fee. Intuitively, marginal prices are inflated above marginal cost for all but the highest type in order to extract larger rents from higher types by discouraging them from selecting a tariff intended for a lower type.

The literature on oligopolistic nonlinear pricing is less well established (see the reviews by Armstrong 2006 and Stole 2007). As discussed further below, there are two branches of this literature that are relevant for our market, where consumers can exhibit unobserved heterogeneity in both their marginal utility of consumption and their brand preferences. The first branch assumes 'one-stop shopping' such that 
consumers can buy, at most, from a single supplier. The second allows 'multi-stop shopping', so that consumers can buy different products from different suppliers, but cannot purchase the same product from more than one firm ${ }^{3}$. We focus on describing the first and simpler branch because the intuition of the results is similar across the two branches.

In the one-stop setting, the related papers by Armstrong and Vickers (2001) and Rochet and Stole (2002) are of particular interest, and we refer to them as AV and RS hereafter ${ }^{4}$. In their simplest form, the results can be presented as follows. Two firms, $j=L, R$, sell a single good, such as electricity, and are located at either end of a unit line. They have symmetric per-consumer costs, $C(q)$. In a one-shot game, each firm simultaneously sets a price-quantity schedule, $T_{j}(q)$, to a unit mass of consumers. The consumers exhibit two forms of unobserved, independent heterogeneity in their tastes, $\{\theta, x\}$. First, as in the monopoly case, consumers are heterogeneous in their marginal utility over all units of consumption, $\theta$. This is labelled as vertical heterogeneity. Second, consumers also exhibit horizontal heterogeneity, as captured by a travel cost which is independent of consumption volume but dependent upon each consumer's location, $x \in[0,1]$, and a transport cost parameter, $\sigma$. A consumer located at point $x$ is then assumed to receive a utility of $U(\theta, q)-\sigma x-T_{L}(q)$ if he purchases $q>0$ units from firm $L$ or $U(\theta, q)-\sigma(1-x)-T_{R}(q)$ if he purchases $q>0$ units from firm $R$. Proposition 1 follows and can be generalised to a multi-product setting (AV) and to an $n$-firm oligopoly (RS, Proposition 7$).^{5}$

\footnotetext{
${ }^{3} \mathrm{~A}$ third branch allows consumers to buy the same product from different suppliers, but this assumption is clearly inappropriate for the present market (e.g. Martimort and Stole 2009).

${ }^{4} \mathrm{RS}$ present their model in the context of quality, rather than quantity, discrimination, but as the two forms are often interchangeable, we refer to their results in the context of quantity discrimination.

${ }^{5}$ Specifically this follows from i) AV Proposition 5 for the case of a single good, where uniqueness is further demonstrated in Armstrong and Vickers (2006, Proposition 1) and ii) RS Proposition 6 under the assumption of a symmetric distribution. AV allow $\theta$ to be multi-dimensional and place no restrictions on its distribution or the form of the utility function but present their results with the assumption that $x$ is distributed uniformly. They also assume the firms have a marginal cost, $c$, and
} 
Proposition 1. Under the assumptions that i) the market is covered in equilibrium for all types; horizontal preferences are ii) independent of vertical preferences and iii) symmetrically distributed, and iv) production costs are symmetric, the unique symmetric equilibrium involves both firms offering a single, identical two-part tariff, $T(q)=F+p q$, where the marginal price is equal to marginal cost, $p=C^{\prime}(q)$.

Thus, in contrast to the wide variety of largely non cost-related tariffs that would be offered by an optimising monopolist, the introduction of competition may prompt firms to adopt a single, identical two-part tariff. Further, with the terminology of $\mathrm{AV}$, the equilibrium tariff will be 'cost-based' in the sense that the marginal price equals marginal cost.

The intuition of Proposition 1 can be understood as follows. Suppose vertical preferences were known to firms. Then, in response to a rival's choice of the proposed cost-based tariff, a firm would optimally offer each consumer its efficient quantity for a total price of $\left(F+C^{\prime}(q) q\right)$. However, even when vertical preferences are unknown, such a strategy can still be implemented by using the proposed two-part tariff because the cost-based marginal price ensures efficient consumption. No other symmetric equilibrium can exist because a supplier would always be able to increase its profits by offering the more efficient cost-based two-part tariff to generate a higher consumer surplus. Due to the associated technical difficulties, the possible existence of asymmetric equilibria remains an open question.

The spirit of Proposition 1 continues within the multi-stop shopping branch of literature, where consumers can buy different products from different suppliers. There, Armstrong and Vickers (2010) demonstrate that under similar conditions to Proposition 1 (assumptions i)-iv)), firms may also employ cost-based tariffs. In the two

a fixed cost per consumer, $k$. RS allow $x$ to be drawn from any distribution which is symmetric and $\log$ concave but assume the utility function and the distribution of $\theta$ and are such that the single crossing property holds, and that the costs functions are strictly convex. Related results can also be found in Thanassoulis (2007) under the assumption that consumers can only buy one or two units. 
good case, they show that firms set one cost-based tariff for each good and offer a lump-sum discount to consumers who buy both goods ${ }^{6}$.

We now consider how applicable these findings are to our present study by assessing the relevance of Proposition 1's assumptions, i)-iv), in respect to the UK electricity market. We then draw on other theoretical work to examine how the predictions might change once each assumption is relaxed. While the findings often differ to Proposition 1, we stress that there is no relevant theoretical explanation for the existence of asymmetric tariffs that are unrelated to differences in production costs.

3.1. Market coverage. The assumption of market coverage is unexceptionable given that electricity is universally available in the $\mathrm{UK}^{7}$. Indeed, Armstrong and Vickers (2010) cite the UK electricity market as a motivating example for their model. However, we know that if this is not the case, then within a symmetric equilibrium, firms are likely to select a menu of non-cost-based tariffs, more akin to the monopoly prediction (Yang and Ye 2008).

3.2. Independent heterogeneity. There is no obvious a priori reason why vertical and horizontal preferences should not be independent in the market. However, Bonatti (2011) lets buyers with stronger brand preferences also have stronger vertical

\footnotetext{
${ }^{6}$ Specifically, the two goods $i=1,2$, have symmetric marginal costs, $c_{i}$. Consumers again exhibit independent horizontal and vertical heterogeneity, but horizontal heterogeneity is now expanded to include an independent location parameter for each good, $\left\{x_{1}, x_{2}\right\}$. As in our market, consumers can choose to purchase both goods from the same firm or buy one good from each supplier for an extra shopping cost of $z \geq 0$. The firms' choices can be disaggregated into a tariff for consumers who just buy good 1, a tariff for consumers who just buy good 2, and a two-product tariff for consumers who buy both goods. Assuming that all consumers buy both goods in equilibrium, Armstrong and Vickers (2010, Proposition 3) demonstrate the existence of a symmetric equilibrium where each firm sets three cost-based two-part tariffs, where the two-product tariff is composed of the sum of the single product tariffs minus a lump sum discount.

${ }^{7} 8 \%$ of households, mainly in rural areas, are not connected to the gas network. Of the remainder, 95\% consume gas (Office of Fair Trading (2011) annex A table A3 p.8).
} 
preferences and demonstrates that firms will offer a menu of tariffs in a symmetric equilibrium $^{8}$. See also Sonderegger (2011) who further allows firms to be endowed with an exogenous, equal share of captive consumers.

3.3. Symmetric horizontal (brand) preferences. As later detailed in Section 5.2 , brand preferences may not be symmetric in our market because some consumers may favour the incumbent. The theoretical effects of an asymmetric distribution of brand preferences are examined under one-stop shopping by RS (Proposition 6). They find that firms still employ cost-based two-part tariffs in equilibrium but the tariffs are no longer identical, with the favoured firm setting a relatively higher fixed fee.

3.4. Cost symmetry. As explained in Section 5.1, there may be some limited cost asymmetries within the market. While little is known about the effects of asymmetric costs, Yin (2004) provides some insight within a special case where firms are constrained to use only two-part tariffs and where there is no vertical heterogeneity. In equilibrium, firms' tariffs can be asymmetric but they remain cost-based in the sense that each firm sets its marginal price equal to its marginal cost.

In summary, theory predicts that firms will offer a single, identical two-part tariff under assumptions i)-iv). If assumptions i)-iv) fail to hold, the existing literatures suggests firms may either offer a symmetric menu of non-cost-based tariffs or offer asymmetric cost-based tariffs. There is no relevant theoretical explanation, consistent with our later empirical findings, for why firms might select asymmetric non-cost based tariffs. ${ }^{9}$

\footnotetext{
${ }^{8}$ Related results can also be found in Stole (1995) under the further assumption that either consumers' vertical preferences or horizontal preferences are observable, and in Yin (2004) where transport costs are dependent upon consumption volume.

${ }^{9}$ In the context of quality rather than quantity discrimination, Champsaur and Rochet (1989 and 1990) show how duopolists can optimally select asymmetric quality and prices. In a two-stage game, the firms each pre-commit to producing a single, asymmetric quality level, before then selecting
} 


\section{The Data and Stylised Facts}

After describing the data and the incumbents' tariffs before market liberalisation, this section uses some simple descriptive statistics to set out three stylised facts regarding firms' tariffs post-liberalisation which are directly relevant to the propositions from the theoretical literature above.

The database of tariff structures is observed at the individual firm level within each of the 14 regions at 14 six-monthly intervals over the period $1999-2005^{10}$. This particular period is deliberately selected to cover two sub-periods: (i) 1999-2002, the three opening years of liberalisation in which there was rapid entry, followed almost immediately by consolidation and exit; and (ii) 2003-5, three years in which consolidation was complete and market structure was stable, leaving just the six firms who have remained in the market to date. The period of observation is ended at 2006 because, from that time onwards, there was considerable volatility in the wholesale market and firms responded by introducing a variety of additional tariffs: tracker deals, fixed-period, green and internet-only tariffs alongside their regular tariffs (Ofgem 2008, figure 7.2, p.75 and pp.92-3.) These later developments take the market beyond the pure setting of non-linear tariffs addressed by the theoretical literature reviewed. All observations and discussion refer to standard credit electricity, which was the default payment method prior to liberalisation and remained the predominant payment method for most of this period (Ofgem, 2004, p.137) ${ }^{11}$.

asymmetric prices. However, it would be inappropriate to transfer this logic to a setting of quantity discrimination, because suppliers cannot commit to marginal prices in the same way as they can to product quality.

${ }^{10}$ The source for these data was price sheets provided in various formats by the Consumers Association and the consumer watchdog, Energywatch. The data was collected in June and December because, for the period under consideration, tariffs rarely changed more frequently than twice a year, and such changes usually occurred in April (and occasionally October) and would have been fully recorded by June and December. Exceptionally, for 1999, the observations relate to February and October to capture the effects of market opening.

${ }^{11}$ As explained in Section 2, alternative methods of payment to standard credit were direct debit 
Prior to liberalisation, each regional incumbent offered consumers only a single two-part tariff, with a fixed fee, $F$ (in pounds per year), and a single marginal price, $p$ (in pence per $\mathrm{kWh}$ ). Figure 2 illustrates the heterogeneity of these tariffs across the 14 regions, partly reflecting geographical differences in distribution cost. Clearly, these recently-privatised incumbent monopolists chose not to offer a menu of multiple two-part tariffs, as theory would predict for a profit maximising monopolist. This might reflect the possible marketing costs of providing multiple tariffs or the firms' reluctance to invoke a regulatory response to a change in industry practice.

In the years after liberalisation, each firm also offered only a single tariff (per payment method). Moreover, only three types of tariff structure were provided: i) a standard two-part tariff, $\{p, F\}$, ii) a tariff with a zero fixed fee, but two marginal prices, $\left\{p^{H}, p^{L}\right\}$, where the higher price, $p^{H}$, was charged on the first $q^{T}$ units consumed, and the lower price, $p^{L}$, applied to all subsequent units consumed, and iii) a three-part tariff, $\left\{p^{H}, p^{L}, F\right\}$, with a positive fixed fee and two marginal prices that followed the structure of (ii).

The standard two-part tariff, (i), was the most common, accounting for $70 \%$ of all tariffs. Tariff structure (ii) accounted for most of the remainder, but we interpret this as little more than a marketing variation on the standard two-part tariff, since the threshold $q^{T}$ was typically set at levels well below the consumption of the vast majority of consumers ${ }^{12}$. Rational consumers using more than $q^{T}$ units should treat and prepayment. Direct debit tariffs typically offer a lump sum discount on standard credit, but differ only slightly across firms and time within the narrow range £8-15 per annum during this period. Prepayment, on the other hand, entailed surcharges on standard credit. Consumers exhibit clear preferences for a particular payment method, which they change relatively rarely, justifying our classification into different markets. In line with the theory above, we focus explicitly only on discrimination in the form of nonlinear pricing and bypass alternative payment methods. In fact, given the lump sum, more or less constant nature of the direct debit discount, our empirical findings below remain qualitatively robust across these two payment methods (Ofgem 2008).

${ }^{12}$ The threshold was $900 \mathrm{kWh}$ or less in $97 \%$ of these cases. Analysis of data reported by the Department of Energy and Climate Change indicates that fewer than $6 \%$ of all households have 
such tariffs as arithmetically 'equivalent' to a standard two-part tariff, with marginal price, $p^{L}$, and fixed fee, $F=\left(p^{H}-p^{L}\right) q^{T}$. The three-part tariff, (iii), only accounted for a small proportion of the tariffs - they were offered only by three firms and had virtually disappeared by 2002. Moreover, the curvature of these tariffs was minimal, with only a small difference between $p^{H}$ and $p^{L}$. This leads to:

Stylised Fact 1: Throughout this period, firms predominantly offered single tariffs, and these were pervasively two-part tariffs.

This therefore provides evidence that is consistent with the first part of Proposition 1 - each firm offered a single two-part tariff. Turning to the second part of the proposition, Figure 3 now investigates the symmetry of tariffs across firms by plotting $F$ against $p$ for each firm ${ }^{13}$. Figure $3(\mathrm{i})$ is based on the pooled database and reveals considerable heterogeneity. Of course, this reflects variability over time and regions as well as between firms, but it is easily shown that there is considerable variability between firms in a given region at each point in time: for example, Figure 3(ii) illustrates variation within the Eastern region in 2000. More generally, in the average year, the within-region standard deviations of $p$ and $F$ are approximately $10 \%$ and $30 \%$ of their respective means, and rising through the period. A standard analysis of variance in each year (not shown) establishes that the dominant source of this dispersion is within-region rather than between-region: within-region variance accounts for $63-97 \%$ of the total variance in $p$ and for $82-97 \%$ of that in $F^{14}$. Since the regional level is the natural definition of the market in this context, most of lower consumption than 900kWh (DECC 2009).

${ }^{13}$ Hereafter, each firm's tariff is expressed in terms of just $F$ and $p$. For the 'equivalent' twopart tariffs, the 'equivalent $F$ ' is computed as described previously. For the three-part tariffs, $p$ is measured by whichever of $p^{H}$ or $p^{L}$ applies for the 'typical' consumer, with $q=3300 \mathrm{kWh}$. This is invariably $p^{L}$.

${ }^{14}$ The remaining, between-region, variance reflects in part differences between regions in distribution costs (see Table 4). 
the ensuing analysis focuses on the within-region variability, and we conclude that, contrary to Proposition 1:

Stylised Fact 2: Firms did not set identical two-part tariffs in the typical market (region).

Figure 4 now uses a simple presentational device to highlight a key aspect of this within-region variability - differences between entrants and incumbents in the same region. Thus, this scatter plots the difference in the fixed fee between each entrant and the incumbent in its region at a given point in time, $F_{E}-F_{I}$, against the difference in their marginal prices, $p_{E}-p_{I}$. This normalisation effectively controls for much of the regional and inter-temporal variability in the data. The frequency of observations within each of the four quadrants of the figure are shown in Table 3 in the 'All' Entrant column. First, consider quadrants II (top left) and IV (bottom right):

Stylised Fact 3: In two-thirds of all cases, the entrant set a higher $F$ and a lower $p$ than the incumbent (quadrant II). Thus, typically, but not always, the entrant's tariff would be relatively more attractive than the incumbent's for higher volume consumers. The reverse was true (quadrant IV) in only $5 \%$ of cases.

Alternatively, by combining quadrants I and II and quadrants III and IV, we can see that, relative to incumbents, entrants set a higher fixed fee in $68 \%$ of cases and a lower marginal price in $92 \%$ of cases respectively. The typical magnitudes of these differentials were $20 \%$ higher for the fixed fee and $10 \%$ lower for the marginal price. These differences were maintained throughout the period, (as later shown in Figures $6(\mathrm{i})$ and $6(\mathrm{ii}))$.

Finally, also note that $25 \%$ of the observations lie in quadrant III (bottom left), where the entrant charged both a lower $F$ and a lower $p$. Thus in one quarter of all cases, the entrant set a tariff which dominated the incumbent's. The reverse was 
true (quadrant I) in only $1 \%$ of cases. Miravete (2011) finds a related result in the US cellular industry, where incumbents offered a greater share of dominated tariffs than entrants.

\section{Some Possible Explanations}

This section now considers two possible explanations for this tariff heterogeneity across firms - asymmetric costs and brand loyalty or market frictions. As a foundation for these discussions, Figures 5(i) and 5(ii) now disaggregate the normalised scattergram of Figure 4 for British Gas and the Majorsaway separately. Since these figures are based on the pooled sample across all years, Figures 6(i) and 6(ii) also show the time paths of the means of $F$ and $p$ across regions for the Incumbents, British Gas and the Majorsaway. ${ }^{15}$

5.1. Asymmetric costs. There are few published data on costs at the individual firm level in this industry, but Table 4 lists and quantifies the five types of cost incurred by electricity retailers. Of these, distribution and transmission are both charges levied on the retailer by upstream firms, and generation is the wholesale costs of electricity. Transmission charges may vary between retailers depending on location of their generation sources and consumers, but these constitute only a very small part of total costs. Distribution charges are regulated to be the same for all retailers in any region. Therefore, any significant cost variations between retailers within a region can only arise from differences in generation and retailing costs.

On generation costs, there is a wholesale market accessible to all retailers. Nevertheless it is often argued that those retailers who are integrated upstream into generation may enjoy some cost advantage over non-integrated firms (Giulietti et

\footnotetext{
${ }^{15}$ Henceforward, the Independents are omitted from all further analysis since very little is known about their likely costs; but since most of these firms had a brief transitory presence in the market and never achieved more than a very minimal market penetration (Table 2), this should be at the loss of little or no generality.
} 
al 2010). If so, this would bestow a marginal cost advantage on the Incumbents, Majorsaway and British Gas, all of whom are vertically integrated, over Independent entrants. However, this would not be a cause of cost asymmetry between Incumbents, Majorsaway and British Gas.

On retailing costs, little is publicly documented. A priori these are more likely related to the number of consumers than the volume of electricity supplied (as discussed in Waddams Price and Hancock 1998), and any asymmetry is therefore likely to affect fixed rather than marginal costs. To the extent that there are asymmetries, it seems likely that they will work in favour of the Incumbents, who should benefit from having established brand names and marketing networks, although this might be offset if entrants benefit from not being locked into legacy retailing operations. Either way however, given that pure retail costs account for only $15 \%$ of all costs, even a $10 \%$ advantage would lead to a cost differential of at most $1.5 \%$, probably in the fixed cost per consumer. In fact, in its energy probe, Ofgem (2008, p.83) estimated that the differential costs between incumbents and others to serve each consumer were trivial at $£ 3$ per year, i.e. around $1 \%$ of a typical electricity bill.

Against this backcloth, consider first the scatter of British Gas-Incumbent differentials (Figure 5(i)). As can be seen, nearly all observations (97\% from Table 3$)$ lie in quadrant II. Thus, in contrast with the earlier aggregate scatter of Figure 4, it was extremely rare for British Gas or the Incumbent to offer a tariff which dominated the other. Rather, because British Gas invariably charged a higher fixed fee but lower marginal price, it was nearly always cheaper for larger volume consumers, while the Incumbent was cheaper for consumers with lower usage. A best fit line through the scatter in Figure 5(i) has a strongly significant slope of -1945 and an insignificant intercept. This implies that British Gas was, in fact, cheaper for all consumers who consumed more than $1945 \mathrm{kWh}$ per year units of electricity. Using Figure 1, this appears to include roughly $80 \%$ of all consumers ${ }^{16}$. Figures 6(i) and 6(ii) confirm that

\footnotetext{
${ }^{16}$ For a consumption level $q^{*}$, the total cost of the British Gas $(B G)$ tariff is less than the incum-
} 
these differences in tariff structure remained throughout the time period.

This result can have no cost-based explanation. As just explained, British Gas and the Incumbents are all vertically integrated, and the only possible asymmetry lay in the pure retail costs, which we have shown are likely to be small if any; moreover British Gas costs would be closer to the Incumbent's because of its own incumbency status in gas. If the two component prices were cost based, all observations in the scatter should lie at, or in the close vicinity of the origin.

We now turn to the scatter for the Majorsaway (Figure 5(ii)). By the same reasoning, any cost differentials relative to Incumbents are likely to be very small and confined to fixed costs per consumer and so most observations should lie on the vertical axis above the origin. As can be seen, this is not the case. Again, most of the scatter lies in quadrant II - the Majorsaway had a higher $F$ but lower $p$ than the Incumbents, such that they were relatively cheaper for higher volume consumers. Figures 6(i) and 6(ii) again confirm that these differentials persist throughout the period.

In this case there are more instances (37\% from Table 3) where the Majorsaways' tariffs dominate the incumbent's at all levels of consumption, because they offer lower fixed fees and marginal prices. But again this is not consistent with cost-based pricing, given no difference in marginal costs and, if anything, higher fixed costs per consumer.

5.2. Brand loyalty or market frictions. By 2005, six years after the last markets opened, only half of consumers had ever switched away from their electricity incumbent, despite potential savings of around 10\% during most of the period (Ofgem 2008). This indicates that some consumers may have favoured the incumbent due to either brand loyalty or the existence of market frictions such as search costs and bent's $(I)$ if $F_{B G}+p_{B G} q^{*}<F_{I}+p_{I} q^{*}$, or $q^{*}>-\left(F_{I}-F_{B G}\right) /\left(p_{I}-p_{B G}\right)$. Thus $q^{*}$ is given by minus the slope of the line through the origin in Figure 5(i). 
switching costs, as explored in an extensive academic and policy literature (e.g. Giulietti et al., 2005, Hartman and Ibáñez, 2007 and Giulietti et al., 2011).

While this literature has examined the implications for tariff levels, it has not considered the implications for the structure of tariffs. However, some insight into the effects of consumers' relative preference for the incumbent can be gained from RS (Proposition 6). As discussed in Section 3.3, RS show that when the distribution of consumers' brand preferences is distributed asymmetrically towards a particular firm, both firms should still select cost-based two-part tariffs with the same marginal price but the favoured (incumbent) firm should set a relatively higher fixed fee. In terms of Figure 4, this would suggest that most observations should be concentrated around the vertical axis (with similar marginal prices) and below the horizontal axis (with a higher incumbent fixed fee). Yet, contrary to this prediction, we observed above that, relative to the incumbent, $68 \%$ of entrants set a higher fixed fee and $92 \%$ set a lower marginal price. Even if BG is excluded because of its own incumbency status in a related market, Figures 6(i) and 6(ii) show as similar pattern for other entrants.

An explanation of brand loyalty or market frictions would also imply certain other regularities. First, we would expect British Gas to offer a tariff with a fixed fee that is relatively closer to the Incumbent than the other entrants, due to its own brand loyalty and prominence as a result of its past incumbency in the gas market, as explained in Section 2. This, at least, seems consistent with the evidence in Figures 5(i) and 5(ii) where the scatter for Majorsaway is, in broad terms, a vertical downwards shift of the British Gas scatter. Second, since the costs of searching and switching to each of the Majorsaway are similar and their brands are largely homogenous, this explanation would also suggest that all Majorsaway should have comparable tariff structures ${ }^{17}$.

\footnotetext{
${ }^{17}$ The Majorsaway each have a national brand presence and each have a similar profile to each other out of their home regions with comparable service and billing offers. Surveys of consumers by Which? suggest that consumers perceive them similarly in terms of service quality (Which? 2011).
} 
But, contrary to this prediction, Figures 7(i) and (ii) reveal that there are significant variations in both the marginal prices and the fixed fees offered by the individual Majorsaway.

In summary, while there is some limited evidence that brand loyalty or market frictions might explain why British Gas charged higher fixed fees than the other entrants, we can reject this explanation for all the other dimensions of tariff asymmetries. Brand loyalty or market frictions cannot explain why entrants predominantly selected higher fixed fees and lower marginal prices than incumbents, nor can they explain the significant asymmetries between the tariffs offered by the different Majorsaway, or the lower marginal prices of British Gas.

\section{Systematic Asymmetry: Evidence of Market Segmentation?}

In the absence of any clear evidence that the tariff asymmetries can be explained in terms of asymmetric costs, brand loyalty or market frictions, the obvious question is whether the findings are sheer noise or whether they are the result of firms' deliberate strategies. In particular, we explore the possibility of an analogy to product differentiation, and examine whether the tariff asymmetries might reflect deliberate and systematic strategies by individual firms to 'distance' their tariffs from each other in order to vertically segment the market by consumers' consumption volumes.

To fix ideas, consider a duopoly in which an incumbent I and an entrant E each offer a single two part tariff but where the entrant sets a higher fixed fee but lower marginal price, as displayed in Figure 8(i). The entrant therefore sells to all consumers with desired consumption more than $q^{*}$, and the incumbent sells to smaller volume consumers. This appears to be consistent with the British Gas-Incumbent differentials observed in Figure 5(i).

More generally, with $(N-1)$ entrants, each offering a different non-dominated tariff, consumers are segmented into $N$ groups by usage and with each firm being cheapest for one group, as illustrated in Figure 8(ii). From Section 3, there appears 
to be no theoretical explanation of how such an outcome might constitute a competitive equilibrium. However, it may be possible this outcome could be a collusive equilibrium in that it qualitatively approximates an optimising monopolist's menu of $\mathrm{N}$ two-part tariffs. This outcome would earn higher aggregate profits than would a monopolist constrained to offer only a single two-part tariff.

This section now continues by identifying whether the observed tariff asymmetries exhibit robust features over time and across regions in a way that could be consistent with such a systematic segmentation. To do this, we introduce a simple statistic to summarise any two-part tariff. As shown in (1) below, the Fixed to Marginal (FM) ratio is simply the ratio of the fixed fee, $F$, to the marginal price, $p$, normalised for a representative consumer with median annual consumption, 3300kWh. The normalisation is unexceptionable and is used merely to invest the ratio with an obvious intuitive meaning: the ratio of charges collected via the fixed fee to charges collected through the marginal price for the typical consumer. Graphically, in Figure 8(ii), we can see that the tariffs $T_{1}(q)$ to $T_{4}(q)$ are increasing in the FM ratio.

$$
F M=(F / p) / 3300=(F / 3300 p)
$$

The overall mean value of FM for the pooled dataset is 0.22 . Deflating alternatively for a high (low) volume consumer with 4950kWh (1650kWh) yields typical values of $0.15(0.40)$. Across regions, the mean value of FM remained stable during the first part of the period, before declining steadily in the second part, as marginal prices rose to reflect higher wholesale costs from 2003 (Giulietti et al 2010).

Asymmetry, as measured by the standard deviation of FM equals 0.075 over the pooled sample. It rose sharply in the second part of the period after initial stability in the first part. Decomposing the variance of FM by region, within-region variance dominated throughout, accounting for about $90 \%$ of the total variance, and rising further in the later years. This confirms that it was asymmetry between firms within regions (i.e. individual markets) which was the main cause of dispersion - as was also 
found above for the component parts $(F \text { and } p)^{18}$.

Inter-firm differences in the FM are depicted first at an aggregate level in Figure 9. Figure 9(i) plots the time paths of mean FM over the period for British Gas and the Incumbent (averaged across the incumbents in the 14 regions). This confirms that British Gas consistently set the higher FM ratio - as was obvious given the above finding that British Gas set higher $F$ and lowerp than Incumbents. This corresponds then to the asymmetric duopoly of Figure 8(i), in which the entrant targets the higher volume consumers. There is no tendency for this asymmetry to disappear over time. Figure 9(ii) then adds in the five Majorsaway, for each firm showing its average FM ratio across all regions in which it was an entrant. Visual inspection suggests that in the early years there was a broad dichotomy, with three firms (Powergen, SSE and EDF) choosing FM ratios fairly close to the incumbents', and the other two (SPower and NPower) positioning themselves close to British Gas. Thereafter however, the dichotomy appears to largely disappear, to be replaced by a fanning out more consistent with Figure 8(ii).

However, this only reports the across-region averages, and the data can be more closely examined at the disaggregated regional level in terms of equation (2), where the differential between each entrant E's FM ratio, $\mathrm{FM}_{E j t}$, and the incumbent's FM ratio, $\mathrm{FM}_{I j t}$, in region $j$ at time $t$ is allowed to vary between the six entrants (BGAS, SP, NP, EDF, SSE and POW) and across the 14 regions, as captured by the region

\footnotetext{
${ }^{18}$ Decomposing alternatively by firm, it is the between-firm component which dominates, but less heavily so. Given that within-region dominates the by-region decomposition, it is unsurprising that between-firm dominates the by-firm decomposition, since they are largely two sides of the same coin. In the extreme case where all firms set the same $F M$ ratio in all regions, but $F M$ differs between firms, within-region and between-firm variance would be identical, and would both account for $100 \%$ of the total variance in their respective decompositions. The fact that within-region variation accounts for a larger share than between-firm adds a further insight. It shows that firms do not simply apply the same tariff nationwide across all regions, even after allowing for regional cost differences.
} 
fixed effects, $\alpha_{j}$ for $j=1, \ldots 14$.

$F M_{E j t}-F M_{I j t}=\beta_{0} B G A S+\beta_{1} S P+\beta_{2} N P+\beta_{3} E D F+\beta_{4} S S E+\beta_{5} P O W+\alpha_{j}+\varepsilon_{i j t}$

The equation is estimated using pooled OLS for two separate time periods - the first two years immediately post-liberalisation (Estimation I) and for the remaining four years, 2002-2005 (Estimation II). The results are presented in Table 5.

First consider the earlier period in Estimation I. Since the equation includes only dummy variables it is the equivalent of an analysis of variance depicted in regression format. The magnitudes of the firm fixed effects confirm the earlier results from the aggregate data: British Gas and two of the Majorsaway (SP and NP) set a FM ratio which was about 0.1 (10\% points) higher than the Incumbents', while the other three Majorsaway opted for a FM ratio which was within 0.01 (1\% point) of Incumbents. More formally, t-tests and Wald tests on the estimated coefficients are used to establish groups of firms that are insignificantly different from each other, yet significantly different from firms in other groups. The results of these tests are shown in the lower part of the Table. The 'lower' Majorsaway form one group along with the Incumbents, while at the higher end, the two Majorsaway and British Gas form another. These results confirm the initial dichotomy. The overall fit of the equation is high: the $R^{2}$ shows that $88 \%$ of the overall variance is explained by these dummy variables alone. This confirms that the asymmetries are largely stable and predictable over this opening phase.

In the later period, 2002-2005, Estimation II shows that this simple high-low dichotomy largely disappears. Most noticeably, relative to the Incumbent, one of the high-end firms (NPower) moved down to a much lower FM ratio; whilst two of the low-end firms (SSE and Powergen) reduced their FM ratios even further to be significantly lower than the Incumbents'. Wald tests for significant differences between coefficients (at the 10\% level) establish the following descending ranking in FM ratios: $\{$ SPower $\} ;\{$ British Gas $\} ;\{$ NPower, EDF $\} ;\{$ Incumbent $\} ;\{$ SSE and 
Powergen $\}$. The simple dichotomy has been replaced by 'fanning out'.

While still focussing on the later period, Estimation III now introduces a dynamic element into the model by including the lagged endogenous variable as an explanatory variable, (3).

$$
\begin{aligned}
F M_{E j t}-F M_{I j t}= & \beta_{0} B G A S+\beta_{1} S P+\beta_{2} N P+\beta_{3} E D F+\beta_{4} S S E \\
& +\beta_{5} P O W+\gamma\left(F M_{E j t-1}-F M_{I j t-1}\right)+\alpha_{j}+\varepsilon_{i j t}
\end{aligned}
$$

This adds an intertemporal element, albeit in a reduced-form way, and provides a simple method for capturing the possibility that the firms' FM ratios are converging towards (potentially different) long-run equilibrium levels. In the usual way in adjustment models of this form, the long-run equilibrium is identified as the ratio of the intercept to the complement of the adjustment parameter. As an illustration, (4) provides the expression for the long-run equilibrium FM ratio differential for British Gas in region $j$.

$$
\left(F M_{E j t}-F M_{I j t}\right)^{*}=\left(\alpha_{j}+\beta_{0} B G A S\right) /(1-\gamma) \text { for } \gamma<1
$$

As can be seen from Table 5, the inclusion of this variable raises the explanatory power from $69 \%$ in Estimation II to $85 \%$. The estimated coefficient on the lagged endogenous variable is significantly lower than unity, implying convergence to equilibria. The magnitudes of the firm-specific equilibrium FM ratios confirm exactly the rank ordering from Estimation II, although the significance of Wald tests is lowered in some cases - notably, for EDF and SSE relative to the incumbents. However, the inclusion of the lagged dependent variable as an explanatory variable inevitably casts some doubts on bias in the estimates. Therefore, as a check, the model was re-estimated normalising the dependent variable by the region mean differential at time $t$, this obviates the need to include region effects in the equation. The coefficient on the lagged endogenous variable is now 0.809 , and still strongly significantly 
smaller than unity, the ranking and relative magnitudes of the firm level coefficients are unchanged from those shown for Estimation III. ${ }^{19}$

It should be stressed again that these results should be interpreted as largely descriptive, nevertheless, even under cautious examination, they do establish two final stylised facts:

Stylised Fact 4: At any point in time, the FM ratios of the individual entrants relative to the incumbent are robust across different markets (regions).

Stylised Fact 5: Over time, the positioning of firms' FM ratios evolved away from a clearly dichotomous clustering, in which the Majorsaway clustered around either British Gas or the Incumbent, towards a fanning out where the market offered a wider variety of FM ratios both below and above that of the Incumbent.

Contrary to the existing theoretical predictions, these findings suggest that firms may have chosen to deliberately differentiate their FM ratio. Indeed, the findings appear consistent with an increased awareness by entrants that segmentation of the market by consumer volume might be preferable to a simple strategy of matching the tariff structure of either the incumbent or the main entrant.

\footnotetext{
${ }^{19}$ In Table 5, and throughout the paper, all mean differences between Majorsaway and Incumbents are interpreted as entrant-incumbent differentials. However, since the Majorsaway are the same set of firms as the Incumbents, these mean differences can also be viewed as differences between the tariffs these firms set when selling 'away' as opposed to at 'home'. When viewed in this way, the results in the Table might imply that these firms merely adopt a national pricing policy in away regions, with a uniform tariff structure in all regions in which they are not incumbents, i.e. identical and higher FM when selling away compared to selling at home. However, this is not the case, as can be shown by re-running estimations I and II without the region fixed effects. The value of $R^{2}$ drops to 0.57 and 0.60 respectively, confirming that there is a significant region-specific dimension to the asymmetry, which would not be the case if the Majorsaway were national pricing when selling away.
} 


\section{Discussion and Conclusions}

This paper has confronted the results from some recent developments in the theory of oligopolistic nonlinear pricing with the evidence of a case study of the first six years of the liberalised British electricity market. As suggested by theory, firms offered single two-part electricity tariffs. However, contrary to the predictions of current theory, suppliers varied considerably and systematically in their chosen tariffs. Relative to the incumbent, the main entrant, British Gas, selected a tariff with a consistently higher fixed fee and lower marginal price, making it more attractive to households with higher usage. This is a pervasive result, applying in all regions and at all points in time. There also appears to be systematic variation in the fixed fees and marginal prices offered by the other four major entrants. In the years immediately after liberalisation, these firms opted for tariffs with fixed to marginal (FM) ratios which were either very similar to that of the incumbent or British Gas. However, during the second part of the period, when market structure had stabilised, this pattern of 'bilateral clustering' gave way to outcomes which can be described as a 'fanning out', in which firms began to select tariffs with FM ratios that differed from each other. This resulted in the market becoming segmented between the firms with each being relatively attractive to different groups of consumer depending on their electricity usage.

The paper largely rejects the possibility that these asymmetries can be accounted for by asymmetric costs or variations in brand loyalty or market frictions. However, it is possible that part of their explanation might lie in the institutional details of the market. Pre-liberalisation, governmental expectations of incumbents to serve low-income consumers may have led to a downward distortion in their FM ratios (see for example Giulietti and Waddams Price 2005), and this may have persisted into the post-liberalisation era due to price regulation in the early years and potential consumer and informal regulatory resistance afterwards. On the other hand, this fails to explain the systematic and increasing heterogeneity between different entrants. 
Consequently, to our knowledge, there is no current theoretical explanation of how the observed asymmetries might form a non-cooperative oligopolistic equilibrium. Existing theory focuses on the characterisation of symmetric equilibria and offers few insights into the possibility of tariff asymmetries, such as those documented here. However, future theoretical work to understand these issues better would appear valuable. In particular, it remains open whether the differentiation of tariffs should be interpreted as the result of unilateral behaviour by firms designed to soften competition; or of tacitly collusive behaviour approximating a monopolist's optimal menu of two-part tariffs as part of a collusive equilibrium, by each offering a different single two-part tariff, within a setting of repeated (multi-market) interaction. ${ }^{20}$

\section{References}

[1] Armstrong M. (2006) "Recent Developments in the Economics of Price Discrimination" in "Advances in Economics and Econometrics: Theory and Applications, Ninth World Congress of the Econometric Society, Volume II", Chapter 4, Blundell, Newey and Persson (eds), Cambridge University Press

[2] Armstrong, M. and Vickers, J. (2001) "Competitive Price Discrimination" RAND Journal of Economics vol. 32 p.579-605

[3] Armstrong, M. and Vickers, J. (2006) "Competitive Nonlinear Pricing and Bundling" University of Oxford, Department of Economics Discussion Paper 281, September 2006

[4] Armstrong, M. and Vickers, J. (2010) "Competitive Non-linear Pricing and Bundling" Review of Economic Studies vol.77 p.30-60

\footnotetext{
${ }^{20}$ Busse (2000) provides related evidence that suggests multi-market contact may enable suppliers to signal their intention to set higher tariffs (across all levels of consumption) by pricing identically across multiple-regions.
} 
[5] Bonatti, A. (2011) "Brand Specific Tastes for Quality" International Journal of Industrial Organization vol.29 p. 562-575

[6] Borzekowski R., Thomadsen R. and Taragin C. (2009) "Competition and Price Discrimination in the Market for Mailing Lists" Quantitative Marketing and Economics vol.7 p.147-179

[7] Busse, M.R. (2000) "Multimarket Contact and Price Coordination in the Cellular Telephone Industry" Journal of Economics and Management Strategy vol.9 p. $287-320$

[8] Busse, M.R. and Rysman, M. (2005) "Competition and Price Discrimination in Yellow Pages Advertising" RAND Journal of Economics vol.36 p.378-390

[9] Champsaur, P. and Rochet, J.-C. (1989) "Multiproduct Duopolists" Econometrica vol.57 p.533-557

[10] Champsaur, P. and Rochet, J.-C. (1990) "Price Competition and Multiproduct Firms" in "Essays in Honor of Edmond Malinvaud" vol.1 p. 162-187, MIT Press

[11] Cohen, A. (2008) "Package Size and Price Discrimination in the Paper Towel Market" International Journal of Industrial Organization vol.26 p. 502-516

[12] Cornwall, N. (2008) "Gas and Electricity Costs to Consumers" published by the National Right to Fuel Campaign

[13] Department of Energy and Climate Change (2008) Quarterly Energy Prices

[14] Department of Energy and Climate Change (2009) Distribution analysis of domestic electricity and gas consumption in Great Britain, confirmed in email correspondence

[15] Giulietti, M., Grossi, L. and Waterson, M. (2010) "Price Transmission in the UK Electricity Market: Was NETA Beneficial?" Energy Economics vol.32 p.1165-74 
[16] Giulietti, M and Waddams Price, C. (2005) "Incentive Regulation and Efficient Pricing Structures" Annals of Public and Co-operative Economics, 76, 1, 1121138

[17] Giulietti M., Waterson M. and Wildenbeest M. (2010) "Estimation of Search Frictions in the British Electricity Market" Working paper

[18] Harker, M. and Waddams Price, C. (2007) "Introducing Competition and Deregulating the British Domestic Energy Markets: A Legal and Economic Discussion" Journal of Business Law p. 244-268

[19] Hartmann, P. and Ibáñez, V.A. (2007) "Managing Customer Loyalty in Liberalized Residential Energy Markets: The Impact of Energy Branding" Energy Policy vol. 35 p.2661-72

[20] Hviid, M. and Waddams Price, C. (2011) "Non-discrimination clauses in the retail energy market", CCP working paper 10-18, forthcoming Economic Journal

[21] Leslie, P. (2004) "Price Discrimination in Broadway Theater" RAND Journal of Economics vol.35 p.520-541

[22] Martimort, D. and Stole, L. (2009) "Market Participation in Delegated and Intrinsic Common Agency Games" RAND Journal of Economics vol.40 p.78-102

[23] Maskin, E. and Riley, J. (1984) "Monopoly with Incomplete Information" RAND Journal of Economics vol.15 p.171-196

[24] McManus, B. (2007) "Nonlinear Pricing in an Oligopoly Market: The Case of Speciality Coffee" RAND Journal of Economics vol.38 p.512-532

[25] Miravete, E.J. (2011) "Competition and the Use of Foggy Pricing" fothcoming, American Economic Journal - Microeconomics 
[26] Mussa, M. and Rosen, S. (1978) "Monopoly and Product Quality" Journal of Economic Theory vol.18 p.301-317

[27] Office of Fair Trading (2011) Off-grid Energy, OFT 1380, annex A

[28] Ofgem (2003) Domestic Gas and Electricity Supply Competition Recent Developments, June

[29] Ofgem (2004) Domestic Competitive Market Review, April

[30] Ofgem (2008) Energy Supply Probe - Initial Findings Report, October

[31] Rochet, J-C. and Stole, L. A. (2002) "Nonlinear Pricing with Random Participation" Review of Economic Studies vol.69 p.277-311

[32] Seim, K. and Viard, V.B. (2011) "The Effect of Market Structure on Cellular Technology Adoption and Pricing" American Economic Journal - Microeconomics vol. 3 p.221-251

[33] Sonderegger, S. (2011) "Market Segmentation with Nonlinear Pricing" Journal of Industrial Economics vol.59 p.38-62

[34] Stole, L.A. (1995) "Nonlinear Pricing and Oligopoly" Journal of Economics and Management Strategy vol.4 p.529-562

[35] Stole, L. A. (2007) "Price Discrimination and Competition" in "Handbook of Industrial Organization Vol.3", M. Armstrong and R. Porter (Eds.) Amsterdam: Elsevier p. 2221-99

[36] Thanassoulis, J. (2007) "Competitive Mixed Bundling and Consumer Surplus" Journal of Economics and Management Strategy vol.16 p.437-467

[37] Waddams Price, C. and Hancock, R. (1998) "Distributional Effects of Liberalising UK Residential Electricity Markets" Fiscal Studies vol.19 p.295- 320 
[38] Which? (2011) Best and Worst Energy Suppliers, accessed 24th November, http://www.which.co.uk/switch/energy-suppliers/best-and-worst-energysuppliers

[39] Yang, H. and Ye, L. (2008) "Nonlinear Pricing, Market Coverage, and Competition" Theoretical Economics vol.3 p.123-153

[40] Yin, X. (2004) "Two-Part Tariff Competition in Duopoly" International Journal of Industrial Organization vol.22 p.799-820 


\section{Tables and Figures}

Table 1: Firm numbers ${ }^{21}$

\begin{tabular}{|l|c|c|c|c|c|}
\hline & Majors & British Gas & Minimajors & Independents & Total \\
\hline Feb-99 & 5 & 1 & 7 & 1 & 14 \\
\hline Oct-99 & 5 & 1 & 7 & 2 & 15 \\
\hline Jun-00 & 5 & 1 & 5 & 3 & 14 \\
\hline Dec-00 & 5 & 1 & 5 & 3 & 14 \\
\hline Jun-01 & 5 & 1 & 5 & 3 & 14 \\
\hline Dec-01 & 5 & 1 & 2 & 3 & 11 \\
\hline Jun-02 & 5 & 1 & 2 & 3 & 11 \\
\hline Dec-02 & 5 & 1 & 2 & 3 & 11 \\
\hline Jun-03 & 5 & 1 & 0 & 2 & 8 \\
\hline Dec-03 & 5 & 1 & 0 & 2 & 8 \\
\hline Jun-04 & 5 & 1 & 0 & 2 & 8 \\
\hline Dec-04 & 5 & 1 & 0 & 1 & 7 \\
\hline Jun-05 & 5 & 1 & 0 & 1 & 7 \\
\hline Dec-05 & 5 & 1 & 0 & 1 & 7 \\
\hline thereafter & 5 & 1 & 0 & 0 & 6 \\
\hline
\end{tabular}

Table 2: Market shares (national averages) ${ }^{22}$

\begin{tabular}{|l|c|c|c|c|}
\hline & Incumbents & British Gas & Majorsaway & Independents \\
\hline 1999 & 90 & $\mathrm{n} / \mathrm{a}$ & $\mathrm{n} / \mathrm{a}$ & 0 \\
\hline 2000 & 80 & 14 & 6 & 0 \\
\hline 2001 & 70 & 17 & 12 & 1 \\
\hline 2002 & 66 & 22 & 12 & 0 \\
\hline 2003 & 60 & 23 & 16 & 1 \\
\hline 2004 & 59 & 24 & 17 & 0 \\
\hline 2005 & 54 & 23 & 23 & 0 \\
\hline
\end{tabular}

${ }^{21}$ Notes: 1. Typically, firms operated in all 14 regional markets. The exceptions are the two Scottish regions, in which there were fewer firms in the earlier periods. 2. The counts of independents are net and conceal turbulence due to entry/exit.

${ }^{22}$ Source: Ofgem (2004) and Table 2.4.1 Percentage of domestic electricity customers(1) by region(2) by supplier type(3), Department of Energy and Climate Change, June 2011 Quarterly Energy Prices, http://www.decc.gov.uk/en/content/cms/statistics/energy_stats/prices/prices.aspx 
Table 3: Relative frequencies (\%) of entrant-incumbent differentials (as shown in Figure 4)

\begin{tabular}{|c|c|c|c|c|c|c|}
\hline Quad & $F_{\mathrm{E}}-\mathrm{F}_{\mathrm{I}}$ & $\mathrm{p}_{\mathrm{E}}-\mathrm{P}_{\mathrm{I}}$ & & \multicolumn{3}{|c|}{ Entrant type } \\
\hline & & & & All & Brit Gas & Majorsaway \\
\hline $\mathrm{I}$ & $>0$ & $>0$ & Incumbent dominates & 1 & 0 & 0.2 \\
\hline $\mathrm{II}$ & $>0$ & $<=0$ & Entrant cheaper for high volume & 67.4 & 97 & 54.3 \\
\hline & 0 & 0 & Symmetry & 1.3 & 0 & 2.4 \\
\hline $\mathrm{III}$ & $<=0$ & $<=0$ & Entrant dominates & 24.7 & 3 & 37 \\
\hline $\mathrm{IV}$ & $<=0$ & $>0$ & Entrant cheaper for low volume & 5.6 & 0 & 6.1 \\
\hline Total & & & & 100 & 100 & 100 \\
\hline
\end{tabular}

Table 4: Retailer costs, $2003^{23}$

\begin{tabular}{|c|c|c|}
\hline Type & $\begin{array}{l}\text { Approx \% of } \\
\text { final price }\end{array}$ & Sources of variability \\
\hline \multicolumn{3}{|c|}{ May differ between retailers within and across regions } \\
\hline Generation & 30 & $\begin{array}{l}\text { A common clearing market should present all retailers } \\
\text { with similar marginal costs, but integrated firms may be } \\
\text { able to hedge volatile wholesale prices more cheaply. }\end{array}$ \\
\hline Retail excluding metering & 15 & $\begin{array}{l}\text { Incumbents may enjoy marketing advantages; entrants } \\
\text { may face consumer inertia and lack of brand name. } \\
\text { Alternatively, entrants may benefit from not being locked } \\
\text { into legacy retailing operations, including bad debts. }\end{array}$ \\
\hline \multicolumn{3}{|c|}{ Differ between regions but identical for all retailers within region } \\
\hline $\begin{array}{l}\text { Distribution charges and } \\
\text { systems losses }\end{array}$ & 34 & $\begin{array}{l}\text { Tariffs regulated and identical for all retailers within a } \\
\text { region, but may differ between regions }\end{array}$ \\
\hline \multicolumn{3}{|c|}{ Unlikely to differ systematically between firms or regions } \\
\hline $\begin{array}{l}\text { Transmission charges and } \\
\text { systems losses }\end{array}$ & 4 & \begin{tabular}{|lllll}
$\begin{array}{l}\text { Charges may differ depending on distance from } \\
\text { generators }\end{array}$ &
\end{tabular} \\
\hline Metering & $\overline{9}$ & Usually shared providers - None \\
\hline VAT \& sundries & 9 & None \\
\hline
\end{tabular}

\footnotetext{
${ }^{23}$ Source: Cornwall (2008), 2001-02 Ofgem distribution tariffs and authors' estimates. Note: VAT on energy is $5 \%$
} 
Table 5: Estimation results for difference between entrant's and incumbent's FM $\operatorname{ratios}^{24}$

\begin{tabular}{|l|c|c|c|}
\hline Estimation & $\mathrm{I}$ & $\mathrm{II}$ & $\mathrm{III}$ \\
\hline Period & $1999.1-2000.2$ & $2001.1-2005.2$ & $2001.1-2005.2$ \\
\hline & Pooled OLS & Pooled OLS & Pooled OLS \\
\hline BGAS & $0.1316^{\star *}$ & $0.0912^{\star \star}$ & $0.0270^{\star \star}$ \\
& $(0.0081)$ & $(0.0081)$ & $(0.0071)$ \\
\hline SP & $0.1057^{\star \star}$ & $0.1032^{\star \star}$ & $0.0291^{\star \star}$ \\
& $(0.0081)$ & $(0.0099)$ & $(0.0084)$ \\
\hline NP & $0.1182^{\star \star}$ & $0.0578^{\star \star}$ & 0.0121 \\
& $(0.0072)$ & $(0.0108)$ & $(0.0084)$ \\
\hline EDF & 0.0111 & $0.0155\left(^{*}\right)$ & 0.009 \\
& $(0.0064)$ & $(0.0085)$ & $(0.0182)$ \\
\hline SSE & -0.0061 & $-0.0353^{\star *}$ & -0.0094 \\
& $(0.0071)$ & $(0.0084)$ & $(0.0072)$ \\
\hline POW & 0.0058 & $-0.0436^{\star *}$ & $-0.0182^{\star \star}$ \\
& $(0.0058)$ & $(0.0088)$ & $(0.0069)$ \\
\hline Lagged Dep & & & $0.7150^{\star *}$ \\
Variable & & & $(0.0411)$ \\
\hline $\mathrm{N}$ & 0.8826 & 0.6936 & 714 \\
\hline $\mathrm{R}^{2}$ & & & 0.8455 \\
\hline
\end{tabular}

Identifiable groups by magnitude of differential (\% points $)^{25}$

\begin{tabular}{|c|c|c|c|c|c|c|}
\hline \multirow[b]{2}{*}{ High } & \multicolumn{2}{|c|}{$\mathrm{T}$} & \multicolumn{2}{|c|}{ II } & \multicolumn{2}{|c|}{ III } \\
\hline & BGAS & 13.2 & SP & 10.3 & SP & 10.2 \\
\hline & NP & 11.8 & BGAS & 9.1 & BGAS & 9.4 \\
\hline & SP & 10.6 & & & & \\
\hline \multirow[t]{2}{*}{ Intermediate } & & & $\mathrm{NP}$ & 5.8 & (NP & $4.2)$ \\
\hline & & & EDF & 1.6 & & \\
\hline Low: Equal to & EDF & 1.1 & Incumbent & 0.0 & EDF & 3.2 \\
\hline \multirow[t]{3}{*}{ Incumbent } & POW & 0.6 & & & Incumbent & 0.0 \\
\hline & Incumbent & 0.0 & & & SSE & -3.2 \\
\hline & SSE & -0.6 & & & & \\
\hline Low: Below & & & SSE & -3.5 & POW & -6.4 \\
\hline Incumbent & & & POW & -4.4 & & \\
\hline
\end{tabular}

\footnotetext{
${ }^{24}$ Notes: 1. Region individual effects not shown (Manweb is default region). 2. Standard errors shown in parentheses; ${ }^{* *}$ denotes coefficient estimate significantly different from zero at the $1 \%$ level, $*$ at the $5 \%$ level, $(*)$ at the $10 \%$ level. 3. Equations are estimated in STATA employing the robust correction.

${ }^{25}$ Groups are identified using Wald tests of restrictions on coefficient estimates in each equation. All firms in each group are insignificantly different from each other but significantly different from those in other groups.
} 
Figure 1: Size distribution of household electricity consumption, 2002-2003 ${ }^{26}$

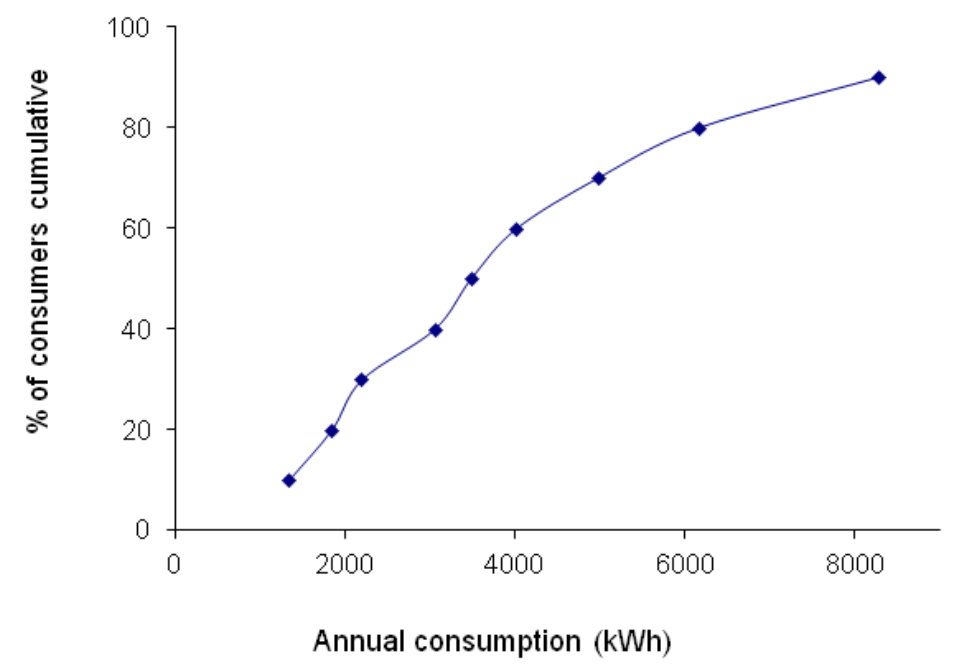

Figure 2: Pre-liberalisation tariffs of incumbents, 1998

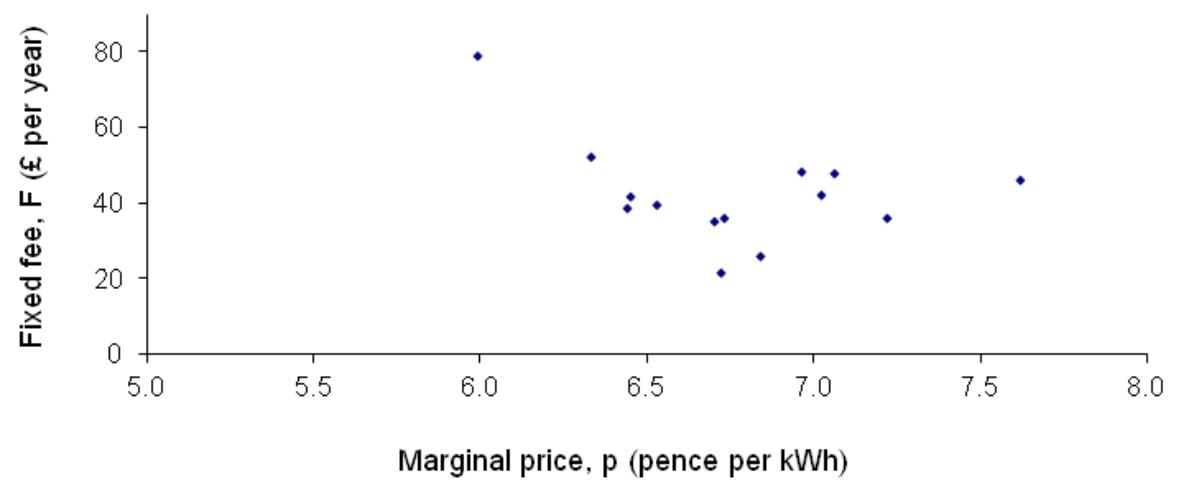

\footnotetext{
${ }^{26}$ Notes: Constructed from data for residential consumers, using standard credit single fuel tariffs, reported in The Expenditure and Food Survey - a stratified representative national sample - for April 2002-April 2003.
} 
Figure 3(i): $F$ against $p$ for all firms, across all regions, across all time periods (pooled data)

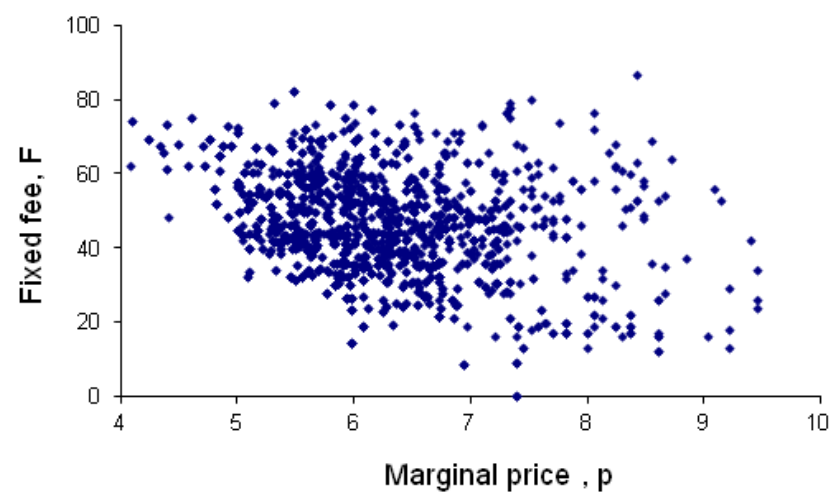

Figure 3(ii): $F$ against $p$ for all firms in Eastern region, June 2000

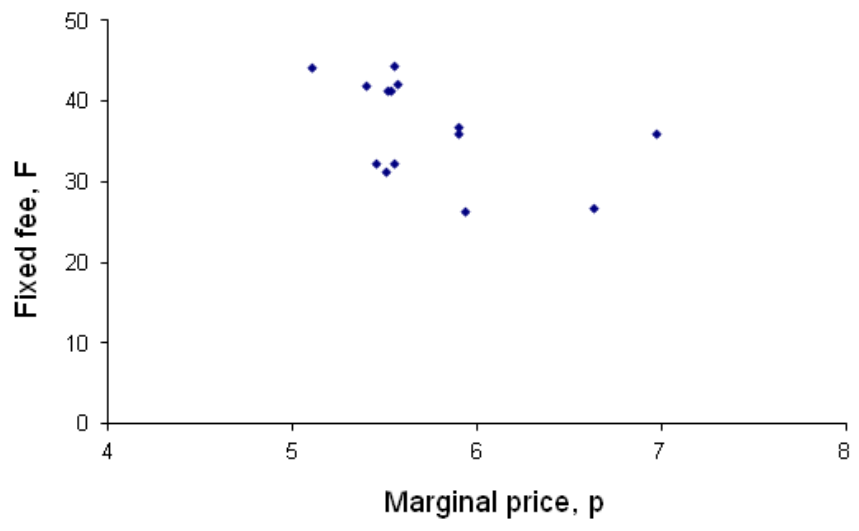


Table 4: Entrant-Incumbent differentials: all entrants

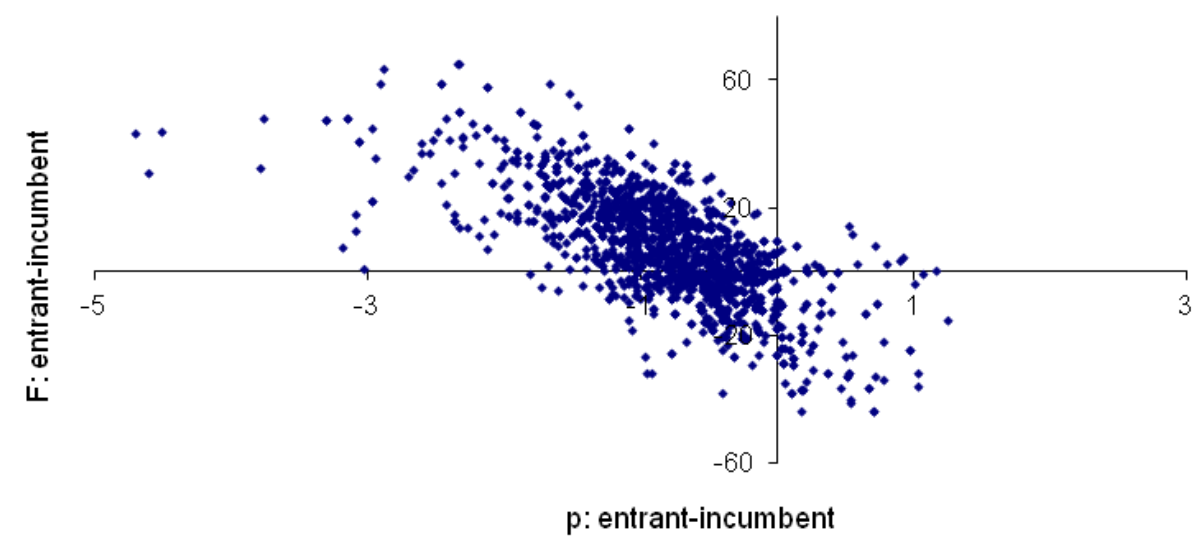


Figure 5(i): British Gas - Incumbent differentials

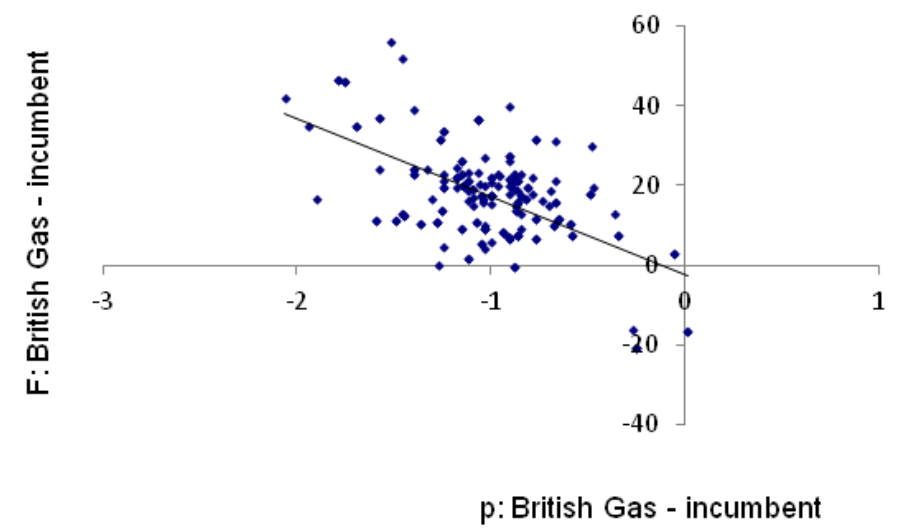

Figure 5(ii): Majorsaway - Incumbent differentials

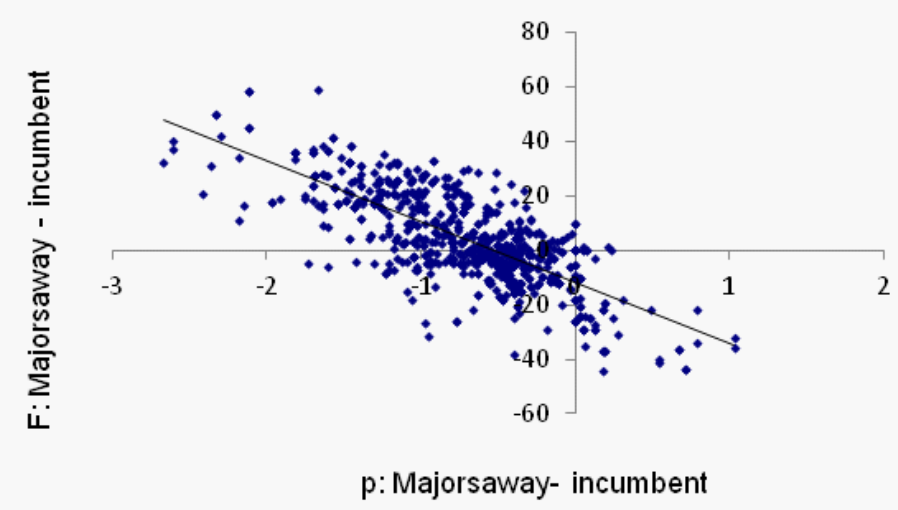


Figure 6(i): Mean $p$ : entrants and incumbents over time

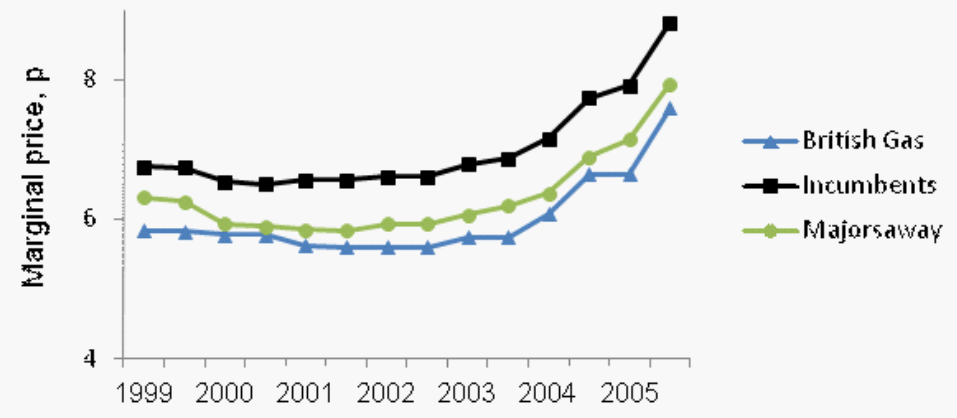

Figure 6(ii): Mean $F$ : entrants and incumbents over time

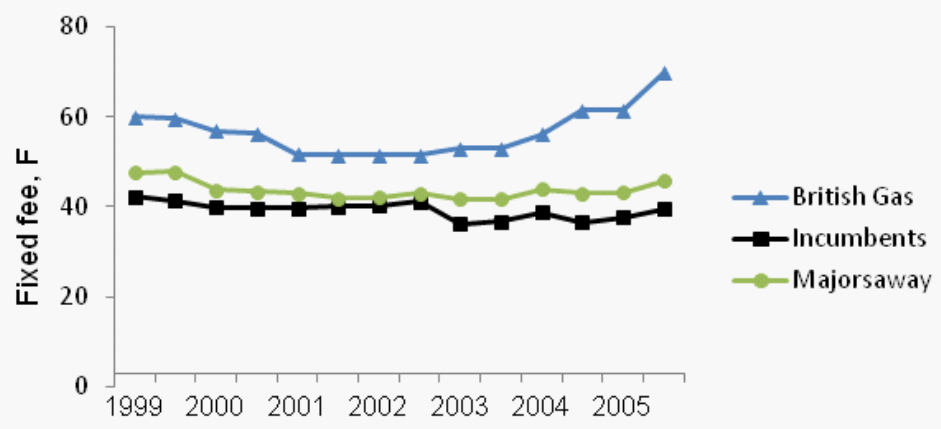


Figure 7(i): Mean $p$ : Individual Majorsaway over time

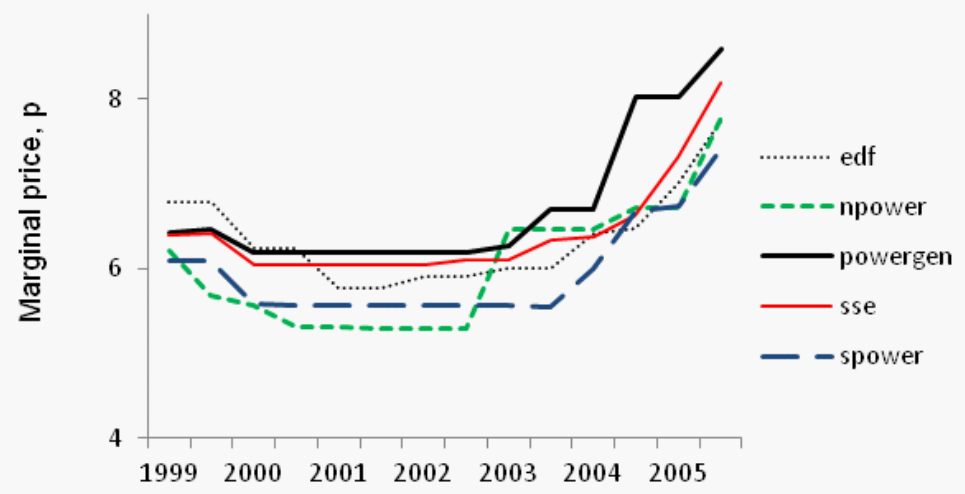

Figure 7(ii): Mean $F$ : Individual Majorsaway over time

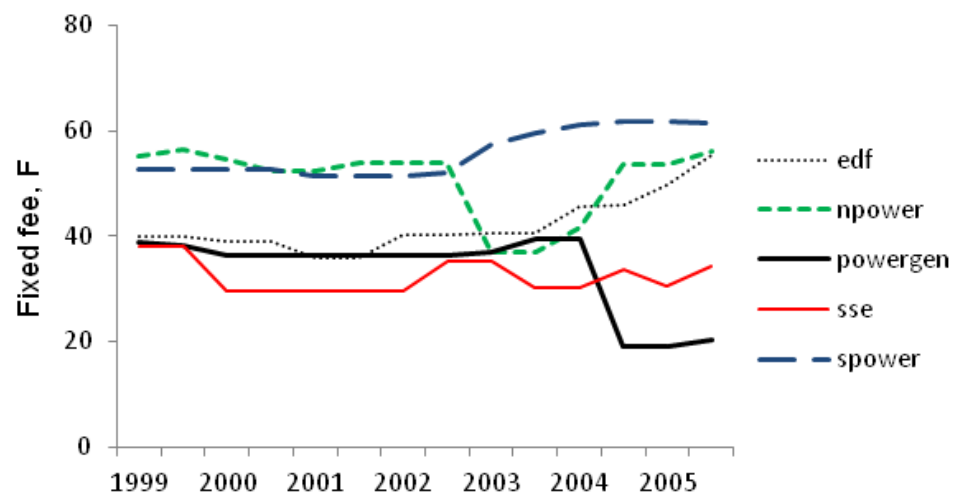


Figure 8(i): Asymmetric duopoly tariffs for entrant, E, and incumbent, I

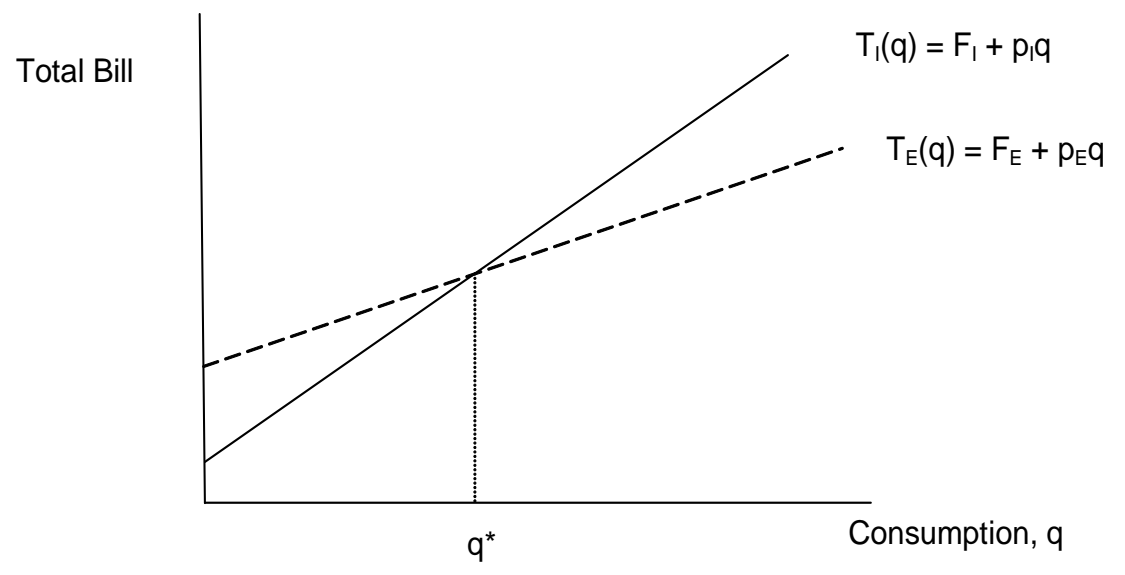

Figures 8(ii): Asymmetric $N$-firm oligopoly tariffs $(N=4)$

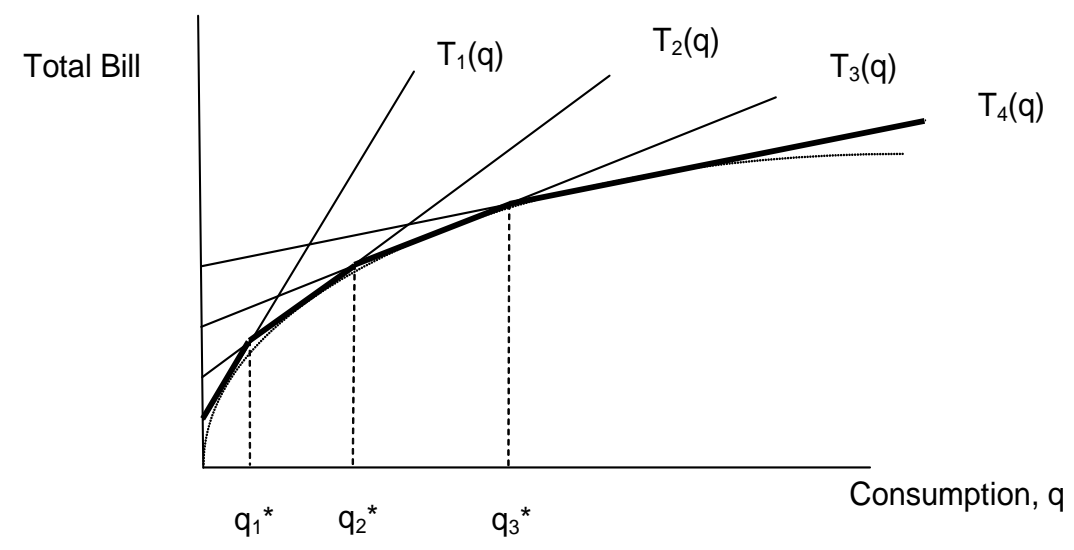


Figure 9(i): Mean FM ratio: British Gas and Incumbents

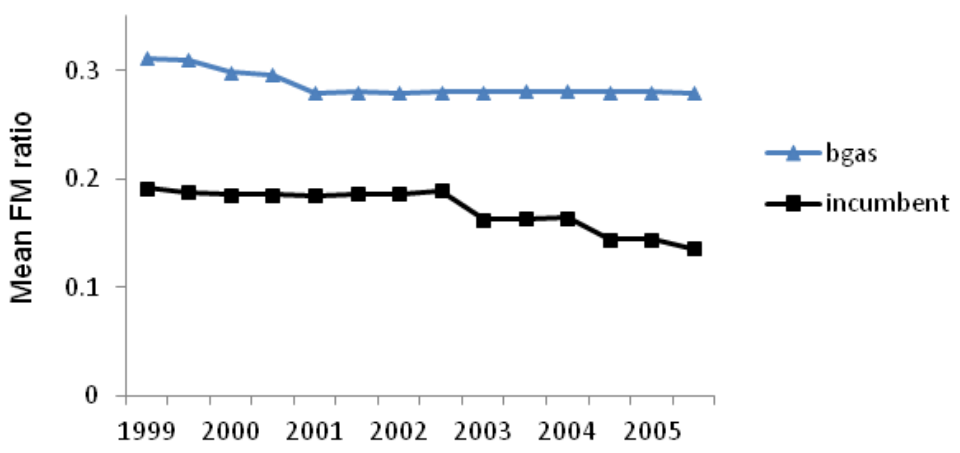

Figure 9(ii): Mean FM ratio: Incumbents and individual firms

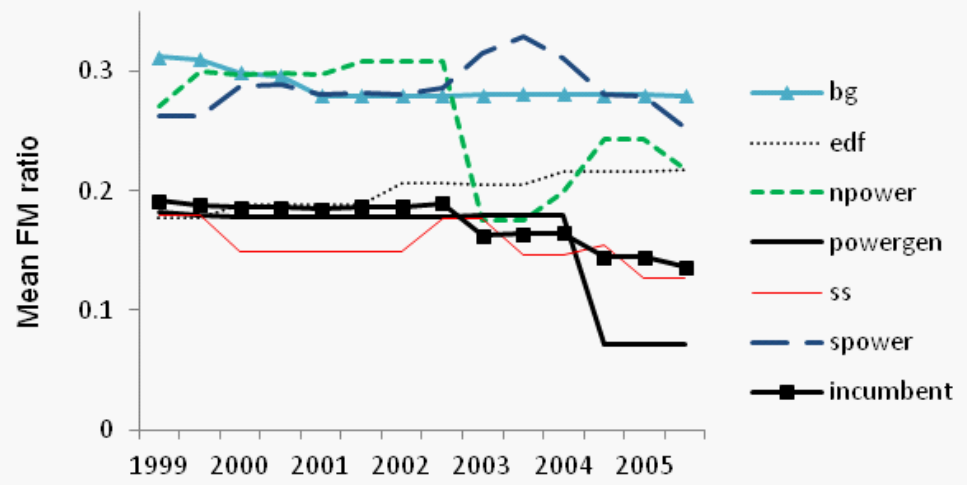

